\title{
Pharmacovigilance of first line anti-tubercular therapy in category I patients of pulmonary tuberculosis
}

\author{
Rahul Agarwal $^{1}{ }^{*}$, Ashok Goel ${ }^{1}$, Jaswant Rai ${ }^{1}$, Nirmal Chand Kajal ${ }^{2}$
}

\begin{abstract}
${ }^{1}$ Department of Pharmacology, GMC Amritsar, Punjab, India ${ }^{2}$ Department of Chest and TB, GMC Amritsar, Punjab, India
\end{abstract}

Received: 18 December 2016 Revised: 25 December 2016 Accepted: 13 January 2017

\author{
*Correspondence to: \\ Dr. Rahul Agarwal, \\ Email: \\ drrahulpharmacology@gmail.co \\ $\mathrm{m}$
}

Copyright: (C) the author(s), publisher and licensee Medip Academy. This is an openaccess article distributed under the terms of the Creative Commons Attribution NonCommercial License, which permits unrestricted noncommercial use, distribution, and reproduction in any medium, provided the original work is properly cited.

\begin{abstract}
Background: Study was done to determine incidence of ADR's in sputum positive, pulmonary TB patients, on DOTS category I and to determine the effect of ADR's on sputum conversion.

Methods: Open, prospective, observational, non-comparative study conducted in the Department of Pharmacology in collaboration with Department of Tuberculosis and Chest Diseases, Government Medical College, Amritsar for the duration of 18 months (March 2015 to September 2016). One hundred sputum positive patients of pulmonary tuberculosis on DOTS category I, of either sex, in age group of 14 years to 65 years, were recruited and followed up during intensive phase of therapy at end of $1^{\text {st }}$ and $2^{\text {nd }}$ month. Causality and Severity assessment were done by using WHO-UMC causality scale and Hartwig's severity scale respectively.

Results: Out of 100 patients $84(84 \%)$ developed one or more ADR's and a total of 118 ADR's occurred in our study. The most common ADR was GI upset $45(38.13 \%)$, followed by hepatitis $42(35.59 \%)$, rash $12(10.16 \%)$, CNS 8 $(6.77 \%)$, arthritic symptoms $5(4.23 \%)$, visual disturbance $2(1.69 \%)$, bleeding problems $2(1.69 \%)$, hyperuricemia $1(0.84 \%)$ and peripheral neuropathy 1 $(0.84 \%)$. Causality assessment revealed that most of ADR's(60) were in probable category and severity assessment revealed that most of ADR's(55) belonged to level 4 (Moderate severity). Most of the ADR's occurred within 30 days of the start of treatment $(84.74 \%)$.

Conclusions: With such a high incidence of ADR's there is a need of incorporating pharmacovigilance programme into this vital health programme for more comprehensive monitoring of tuberculosis patients on DOTS for timely prevention, detection, and management of ADR's. This will decrease non-adherence and dropouts, and thus result in better treatment outcomes.
\end{abstract}

Keywords: Adverse drug reactions, Causality, Severity, Tuberculosis

\section{INTRODUCTION}

Tuberculosis (TB) is a chronic granulomatous infectious disease caused by the bacillus Mycobacterium tuberculosis bacilli (Mtb) which was discovered by Robert Koch in 1882. ${ }^{1}$ TB is an age old dreadful disease and globally, there were an estimated 10.4 million new TB cases with 1.8 million TB deaths in 2015. In India, an incidence of 2.2 million, and prevalence of 2.5 million of TB cases were reported in $2015 .^{2}$ Number of smear positive patients diagnosed in 2015 were 9,02,732 in India and 28,183 in Punjab. ${ }^{3}$ With the discovery of effective chemotherapy against $\mathrm{TB}$, it was expected that the disease would be eventually controlled but then came the problem of adherence to treatment. To overcome this, Directly Observed Treatment (DOTS) was advocated for all tuberculosis patients. In spite of introduction of Short Course Chemotherapy (SCC), there were reports of low compliance to treatment among TB patients because of long duration and Anti-tubercular therapy (ATT) induced Adverse Drug Reaction (ADR's). RNTCP took its route in India in 1993 and currently its main aim is to cure at least $90 \%$ new sputum smear positive patients by $2017 .^{2}$ Though DOTS has certainly overcome the problem of non-adherence, many patients still suffer from one or more ADR's associated with multidrug regimens of antiTB drugs. Adverse drug reactions are said to be an inevitable price we pay for the benefit of any drug 
therapy, so it is important to monitor both the known and unknown side effects of medicines in order to determine any new information available in relation to their safety profile. Given the lower rate of ADR reporting in India, one of the reasons might be attributed to the lack of awareness about pharmacovigilance and ADR monitoring among the Indian healthcare providers. The severity of adverse drug reactions may range from mild to fatal. ${ }^{4}$ However the frequency of occurrence of ADR's to ATT and their causality assessment is not well known, probably due to lack of awareness, detection and under reporting. ${ }^{5}$ The lack of knowledge about the treatment and ATT induced ADR's are the two major factors which lead to the patient's non-adherence to the TB therapy. ATT exhibits greater level of efficacy but with a significant degree of toxicity, especially during $1^{\text {st }}$ and $2^{\text {nd }}$ month of the start of therapy. 6,7 The need of the hour is pharmacovigilance study of anti-tubercular therapy so that early diagnosis and management of ADR's can be done actively, which will further improve patient adherence and treatment outcomes.

The purpose of this study was to determine the incidence of ADR's, time duration of occurrence and effect of ADR's on sputum conversion in newly diagnosed sputum positive pulmonary tuberculosis patients who were on DOTS category I.

\section{METHODS}

Our study was open, prospective, observational, noncomparative study which was conducted in the Department of Pharmacology in collaboration with Department of Tuberculosis and Chest Diseases, Government Medical College, Amritsar. One hundred sputum positive patients, of pulmonary tuberculosis on DOTS category I, of either sex, in the age group of 14 years to 65 years, from out-patient department and patients admitted in wards of the Department of
Tuberculosis and Chest diseases Hospital from March 2015 to September 2016 were recruited.

The approval of Institutional Ethics Committee was taken before the start of study. Written informed consent was taken from patients in their vernacular language. The study subjects on DOTS Cat I were put on Short Course Chemotherapy Regimen comprising of $600 \mathrm{mg}$ Isoniazid(H), 450mg Rifampicin(R), 1200mg Ethambutol(E) and $1500 \mathrm{mg}$ Pyrazinamide(Z). The patients were then monitored for adverse drug reactions for 60 days. Proforma was designed to record detailed history, examinations, laboratory investigations, and ADR's of study subjects. Follow up was done at 30 and 60 days during which patients were actively enquired of any adverse drug reactions and the same were recorded on proforma. Physical characteristics which include body weight, height, BMI, BP and laboratory investigations like CBC, SGOT, SGPT, urea, creatinine, uric acid, sputum microscopy and serum bilirubin were done at 0 , 30 and 60 days. Causality assessment was done by using WHO-UMC causality criteria and severity assessment was done by using Hartwig's severity scale. ${ }^{8,9}$

Demographic characteristics of patients, incidence of various ADR's and their impact on sputum conversion rate were assessed and data was analyzed using Chisquare test $\left(\chi^{2}\right)$ and ANNOVA (F test) test.

\section{RESULTS}

Out of 100 patients recruited in our study, 84(84\%) patients developed ADR's. Most of ADR's (26.19\%) occurred in the age group of 14-25 years Males were more prone to develop ADR's (59.52\%) than females $(40.48 \%)$. Non smokers $(72.62 \%)$, non drinkers (76.19\%), non vegetarians $(59.52 \%)$ and illiterate patients developed more ADR's as compared to smokers $(27.38 \%)$, drinkers $(23.81 \%)$, vegetarians $(40.47 \%)$ and literate $(45.23 \%)$ as shown in Table 1.

Table 1: Baseline characteristics of the patients.

\begin{tabular}{|c|c|c|c|c|c|}
\hline Parameters & & Developed ADR's & Not developed ADR's & $\chi^{2}$ value & p-value \\
\hline \multirow{5}{*}{ Age (years) } & $14-25$ & $22(26.19 \%)$ & $2(12.50 \%)$ & \multirow{5}{*}{11.971} & \multirow{5}{*}{0.018} \\
\hline & $26-35$ & $15(17.85 \%)$ & $1(6.25 \%)$ & & \\
\hline & $36-45$ & $15(17.85 \%)$ & $4(25 \%)$ & & \\
\hline & $46-55$ & $13(15.47 \%)$ & $8(50 \%)$ & & \\
\hline & $56-65$ & $19(22.61 \%)$ & $1(6.25 \%)$ & & \\
\hline \multirow{2}{*}{ Sex } & Male & $50(59.52 \%)$ & $10(62.5 \%)$ & \multirow{2}{*}{0.003} & \multirow{2}{*}{0.956} \\
\hline & Female & $34(40.48 \%)$ & $6(37.5 \%)$ & & \\
\hline \multirow{2}{*}{ Smoking status } & Non smokers & $61(72.62 \%)$ & $12(75 \%)$ & \multirow{2}{*}{0.012} & \multirow{2}{*}{0.912} \\
\hline & Smokers & $23(27.38 \%)$ & $4(25 \%)$ & & \\
\hline \multirow{2}{*}{ Drinking status } & Non drinkers & $64(76.19 \%)$ & $13(81.25 \%)$ & \multirow{2}{*}{0.019} & \multirow{2}{*}{0.907} \\
\hline & Drinker & $20(23.81 \%)$ & $3(18.75 \%)$ & & \\
\hline \multirow{2}{*}{ Dietary pattern } & Vegetarians & $34(40.47 \%)$ & $6(37.5 \%)$ & \multirow{2}{*}{0.003} & \multirow{2}{*}{0.956} \\
\hline & Non-vegetarians & $50(59.52 \%)$ & $10(62.5 \%)$ & & \\
\hline \multirow{2}{*}{ Education status } & Literate & $38(45.23 \%)$ & $5(31.25 \%)$ & \multirow{2}{*}{0.578} & \multirow{2}{*}{0.447} \\
\hline & Illiterate & $46(54.76 \%)$ & $11(68.75 \%)$ & & \\
\hline
\end{tabular}


The most common ADR in our study was GI upset $(38.13 \%)$ and hepatitis $(35.59 \%)$. Frequencies of other ADR's were as shown in Figure 1.

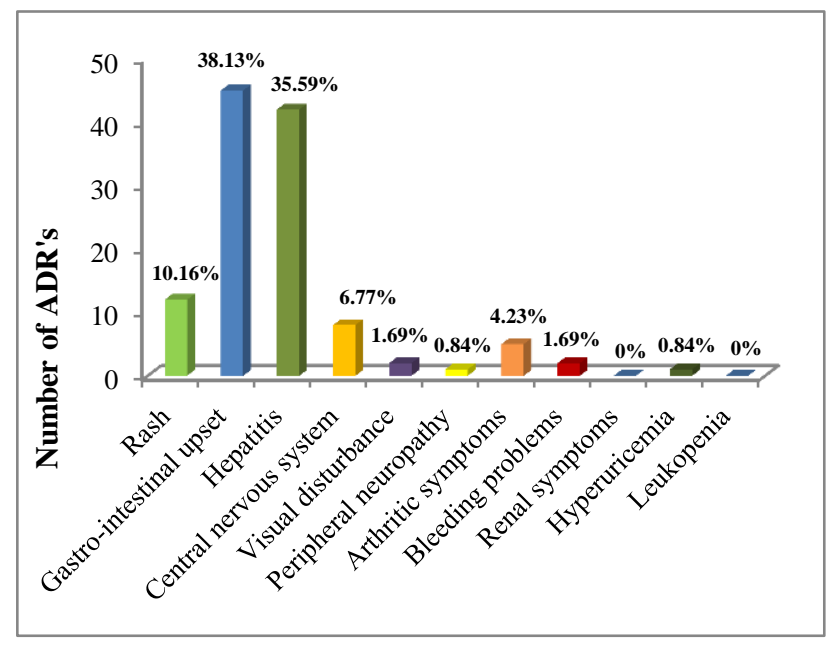

Figure 1: Incidence of various ADR's.

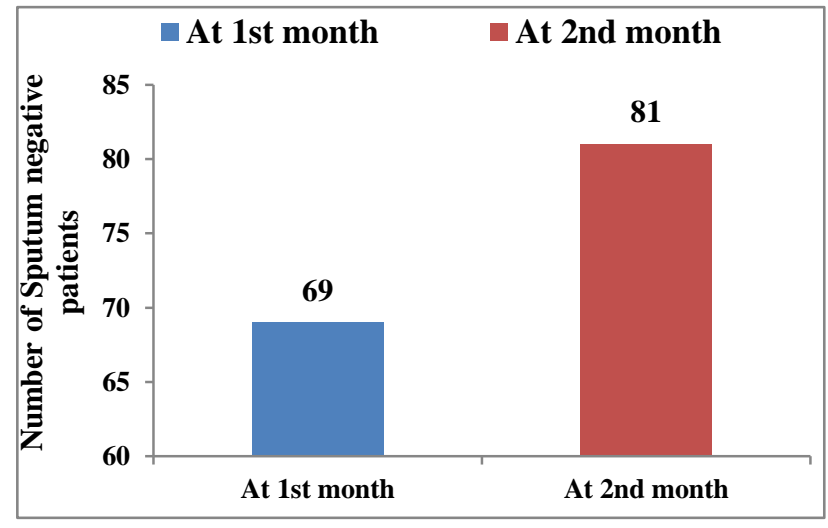

Figure 2: Number of patients converted to sputum negative at the end of $1^{\text {st }}$ and $2^{\text {nd }}$ month.
Sputum Conversion Rate (SCR) at the end of two months of treatment in the patients with ADR's and without ADR's was $79.77 \%$ and $87.5 \%$ respectively as shown in Figure 2.

\section{Table 2: Relationship of occurrence of ADR's with duration of therapy.}

\begin{tabular}{|lll|}
\hline $\begin{array}{l}\text { No. of days of } \\
\text { starting therapy }\end{array}$ & No. of ADR's & Percentage \\
\hline $1-15$ & 59 & 50 \\
\hline $16-30$ & 41 & 34.74 \\
\hline $31-45$ & 11 & 9.32 \\
\hline $46-60$ & 7 & 5.93 \\
\hline
\end{tabular}

Table 2 demonstrates that 59 (50\%) of ADR's occurred within 1-15 days after starting therapy, followed by 41 $(34.74 \%), 11(9.32 \%)$ and seven $(5.93 \%)$ within 16-30 days, 31-45 days and 40-60 days, respectively.

Out of 118 ADR's, 42 (35.59\%) were of drug induced hepatitis. There was a rise in SGOT, SGPT and bilirubin levels at 30 days of treatment, followed by a fall in levels of these laboratory parameters at 60 days as shown in Table 3 . The change in SGOT, SGPT and bilirubin levels at 0,30 and 60 days was statistically significant with pvalue of $0.001,0.011$ and 0.013 , respectively. Mean value of hemoglobin, BMI and body weight increased with duration of treatment but the value was not statistically significant.

Causality assessment of various ADR's as per WHOUMC criteria reveals that majority of cases $60(71.43 \%)$ belonged to probable, followed by $20(23.81 \%)$ cases of possible and four $(4.76 \%)$ cases of certain as shown in Figure 3.

Table 3: Mean change in various parameters at 0,30 and 60 days.

\begin{tabular}{|llllll|}
\hline Parameters & Day 0 & Day 30 & Day 60 & F test & p- value \\
\hline Body weight & $45.84 \pm 10.77$ & $46.97 \pm 10.73$ & $47.95 \pm 10.57$ & 0.975 & 0.378 \\
\hline BMI & $18.13 \pm 3.94$ & $18.58 \pm 3.93$ & $19.01 \pm 3.96$ & 1.224 & 0.296 \\
\hline Hemoglobin & $9.24 \pm 1.81$ & $9.37 \pm 1.49$ & $10.33 \pm 2.88$ & 1.332 & 0.266 \\
\hline WBC & $10525.12 \pm 2498.12$ & $9072.3 \pm 1923.01$ & $8411 \pm 1302.05$ & 34.093 & 0.001 \\
\hline SGOT & $41.13 \pm 12.85$ & $53.24 \pm 26.40$ & $45.87 \pm 18.91$ & 9.159 & 0.001 \\
\hline SGPT & $43.98 \pm 14.90$ & $52.1 \pm 23.91$ & $46.84 \pm 18.06$ & 4.543 & 0.011 \\
\hline Bilirubin & $0.72 \pm 0.45$ & $0.92 \pm 0.90$ & $0.70 \pm 0.20$ & 4.417 & 0.013 \\
\hline
\end{tabular}

From the Figure 4, showing analysis of severity assessment of ADR's on Hartwig's scale, it is evident that most of the cases (55) were of level 4 (moderate) severities where the treatment with suspected drug was withheld and length of stay was more than one day.

\section{DISCUSSION}

Anti-TB drugs could cause significant adverse effects both in magnitude and severity ${ }^{6}$. Results of our study reveal that $84 \%$ of patients developed one or more ADR's and a total of 118 ADR's occurred in our study. 


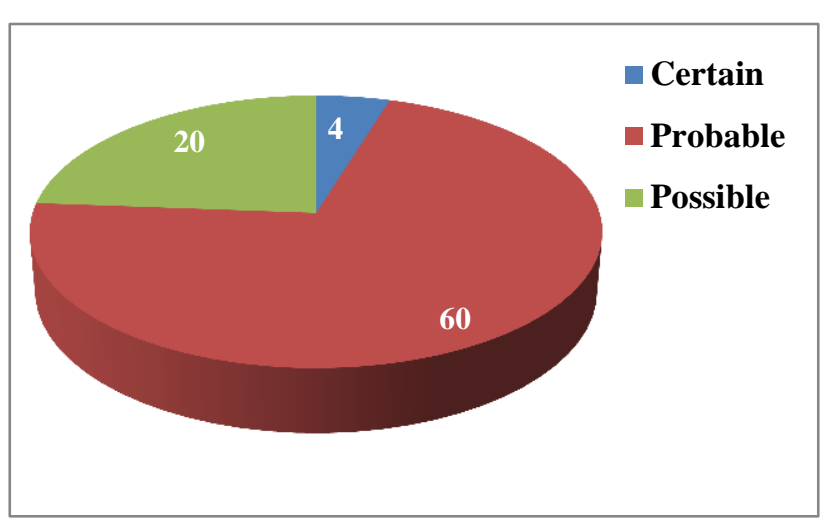

Figure 3: Causality of ADR's as per WHO-UMC causality criteria.

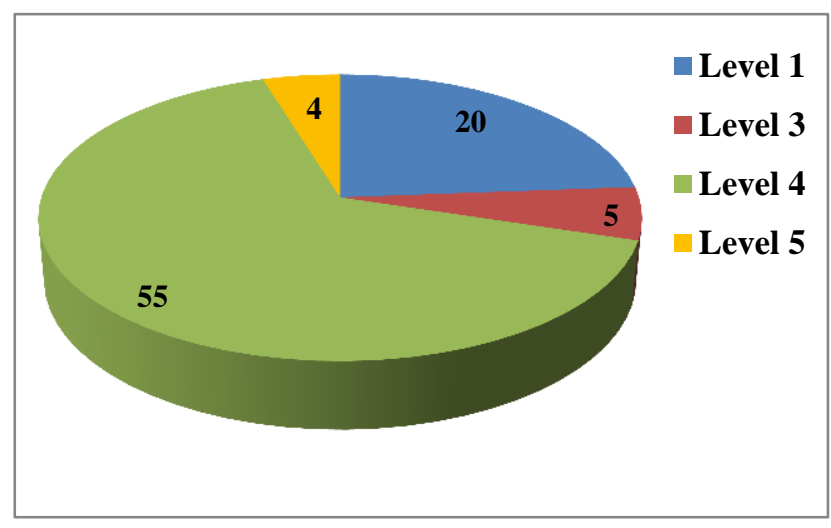

Figure 4: Categories of ADR's as per Hartwigs severity scale.

This relatively high incidence is in concordance with the study done by Koju et al and the study done by Rajanandha et al which showed the incidence of $80 \%$ and 92.5\% respectively. ${ }^{10,11}$ Most common ADR was GI upset $45(38.13 \%)$, followed by hepatitis $42(35.59 \%)$, rash $12(10.16 \%)$, CNS $8(6.77 \%)$, arthritic symptoms 5 $(4.23 \%)$, visual disturbance $2(1.69 \%)$, bleeding problems $2(1.69 \%)$, hyperuricemia $1(0.84 \%)$ and peripheral neuropathy $1(0.84 \%)$. Various other studies like Sahithi et al, Honnaddi et al and Sinha et al also showed higher incidence of gastro-intestinal problems. ${ }^{12-14}$ Out of total 118 ADR's, 59 (50\%) ADR's occur within 1-15 days after starting therapy, followed by 41 (34.74\%), 11 $(9.32 \%)$ and seven $(5.93 \%)$ within $16-30$ days, 31-45 days and 40-60 days, respectively. This is in concordance with the study done by Kheirollah et al and Abideen et al in which maximum number of ADR's were seen within lag period of 1-15 days. ${ }^{6,15}$ Causality assessment revealed that most of ADR's were in probable category and severity assessment revealed that most of ADR's belong to level 4 (Moderate severity).

The study finding of occurrence of majority of ADR's within first 30 days of treatment calls for intensive training of health personnel in identification and timely management of ADR's during this crucial period. There is a need of incorporating pharmacovigilance programme into this vital health programme for more comprehensive monitoring of tuberculosis patients on DOTS. Counseling of patients for timely prevention, detection, and management of ADR's will build confidence of patients, decrease non-adherence and dropouts, and thus result in better treatment outcomes. This emphasizes the importance of developing strategies at the programme level to deal with ADR's both to improve the quality of patients care and to control TB safely.

Funding: No funding sources

Conflict of interest: None declared

Ethical approval: The study was approved by the Institutional Ethics Committee

\section{REFERENCES}

1. Ananthanarayan R. Textbook of microbiology. 9th ed. Hyderabad: University Press (India); 2013:345358.

2. TB India. Part 1: Ministry of Health and Family Welfare. 2016. Available from: http://tbcindia.nic.in/showfile.php?lid=3180.

3. TB India. Part 2: Ministry of Health and Family Welfare. 2016. [cited 2016 Nov 18]. Available from: http://tbcindia.nic.in/showfile.php?lid=3181

4. Bulletin on adverse drug reaction. Lokmanya Tilak Municipal Medical College and General Hospital. 2012 Apr;2(1):40.

5. DiPiro JT. Pharmacotherapy. A pathophysiologic approach. $9^{\text {th }}$ ed; New York: McGraw-Hill; 2014:2586.

6. Gholami K, Kamali E, Hajiabdolbaghi M, Shalviri G. Evaluation of anti-tuberculosis induced adverse reactions in hospitalized patients. Pharm Pract. 2006;4(3):134-8.

7. Chandrasekaran K SAP. Implementation of Self Reporting Pharmacovigilance in Anti Tubercular Therapy Using Knowledge Based Approach. J Pharmacovigil. 2013;1(1). Available from: http://www.esciencecentral.org/journals/implementati on-of-self-reporting-pharmacovigilance-in-antitubercular-therapy-using-knowledge-based-approach2329-6887.1000101.php?aid=10726

8. Edwards IR, Aronson JK. Adverse drug reactions: definitions, diagnosis, and management. Lancet. 2000 Oct 7;356(9237):1255-9.

9. Hartwig SC, Siegel J, Schneider PJ. Preventability and severity assessment in reporting adverse drug reactions. Am J Health Syst Pharm. 1992 Sep 1;49(9):2229-32.

10. Koju D, Rao B, Shrestha B, Shakya R, Makaju R. Occurrence Of Side Effects From Anti-Tuberculosis Drugs In Urban Nepalese Population Under DOTS Treatment. Kathmandu Univ J Sci Eng Technol. 2005 Sep; $1: 9$.

11. Rajanandh MG, Nageswari AD, Ramasamy C, Dinesh V. Side effects of anti tubercular drugs on directly observed treatment strategy under revised national tuberculosis control programme in a 
teaching hospital. Glob J Pharmacol. 2012 Jan 1;6(1):29-32.

12. Sahithi K, Rao GP, Lohith MN, Rao DGC, Umar Pharm. D DKM, Rao Nadendla M. Pharm and Ph.D. FIC PR. Evaluation of incidence and severity of antitubercular drugs induced adverse drug reactions in tuberculosis patients. Eur J Biomed Pharm Sci. 2016;3(8):166-72.

13. Honnaddi DUC, Honnaddi DMU, SR DT, Hossain DT, Somani DR. Adverse Drug Reactions to First Line Anti-Tubercular Drugs - A Pharmacovigilance Study. Int J Pharmacol Res. 2016 Feb 28;6(2):51-4.

14. Sinha K, Marak ITR, Singh WA. Adverse drug reactions in tuberculosis patients due to directly observed treatment strategy therapy: Experience at an outpatient clinic of a teaching hospital in the city of Imphal, Manipur, India. J Associations Chest Physicians. 2013;1(2):50-3.

15. Abideen $\mathrm{P}$, Chandrasekran K, Maheshwaran U, Kumar V, Kalaiselvan V, Mishra P, et al. Implementation of Self Reporting Pharmacovigilance in Anti Tubercular Therapy Using Knowledge Based Approach. J Pharmacovigil. 2013;1(1):5.

Cite this article as: Agarwal R, Goel A, Rai J, Kajal NC. Pharmacovigilance of first line anti-tubercular therapy in category I patients of pulmonary tuberculosis. Int J Basic Clin Pharmacol 2017;6:6437 . 